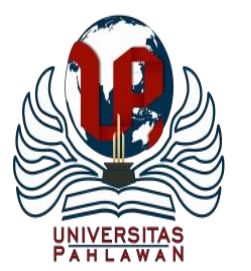

Jurnal Abdidas Volume 2 Nomor 5 Tahun 2021 Halaman 1054-1063

JURNAL ABDIDAS

http://abdidas.org/index.php/abdidas

\title{
Sosialisasi Pemasaran Digital Bagi Pelaku Industri Rumahan di Kabupaten Bangka Tengah
}

\author{
Hilyah Magdalena ${ }^{1 凶}$, Hadi Santoso ${ }^{2}$ \\ Institut Sains dan Bisnis Atma Luhur, Indonesia ${ }^{1,2}$ \\ E-mail : $\underline{\text { hilyah@atmaluhur.ac.id }}{ }^{1} \underline{\text { hadisantoso@ atmaluhur.ac.id }}^{2}$
}

\begin{abstract}
Abstrak
Kondisi masih pandemi dan terbatasnya pangsa pasar, mendorong pelaku industri rumahan melirik peluang yang ditawarkan pemasaran digital. Sosialisasi pemasaran digital yang diberikan kepada pelaku usaha industri rumahan di wilayah Kabupaten Bangka Tengah ini diprakarsai oleh Dinas Pemberdayaan Perempuan Keluarga Berencana Pengendalian Penduduk Perlindungan Anak (DPPKBPPPA). Kegiatan ini bertujuan untuk mendorong laju pertumbuhan ekonomi pelaku industri rumahan agar tidak kehilangan pangsa pasar selama pandemi. Lebih lanjut pengenalan dan pengetahuan memasarkan produk secara digital juga diharapkan mampu memperluas pasar, sehingga produk industri rumahan dapat menembus pasar nasional atau bahkan internasional. Metode kegiatan pengabdian masyarakat ini adalah metode pelatihan yang terdiri dari koordinasi dan diskusi dengan dinas penyelenggara, mempersiapkan materi, melakukan kegiatan sosialisasi, evaluasi kegiatan, dan penyusunan laporan. Kegiatan sosialisasi pemasaran digital ini diberikan dalam lima sesi. Pembagian waktu pelatihan untuk memudahkan peserta memahami beberapa teknik pemasaran digital, mulai dari yang paling sederhana yaitu menggunakan Instant Messaging Marketing, media sosial, sampai membuka toko online. Materi disajikan dengan bahasa sederhana dan contoh yang mudah dipahami dan diikuti peserta. Peserta diajak ikut aktif sejak awal kegiatan, agar mereka dapat praktek langsung cara menggunakan aplikasi digital untuk memasarkan produk mereka. Dengan mengikuti sosialisasi ini, peserta yang merupakan pelaku usaha industri rumahan diharapkan mampu melebarkan pemasaran produknya secara digital.
\end{abstract}

Kata kunci: pemasaran digital, industri rumahan, Bangka Tengah

\begin{abstract}
The condition is still a pandemic and limited market share, encouraging home industri players to look at the opportunities offered by digital marketing. The digital marketing socialization that was given to home industri entrepreneurs in the Central Bangka Regency was initiated by the Office of Women's Empowerment, Family Planning, Population Control, Child Protection (DPPKBPPPA). This activity aims to encourage the pace of economic growth of home industri players so as not to lose market share during the pandemic. Furthermore, the introduction and knowledge of marketing products digitally is also expected to be able to expand the market, so that home industri products can penetrate the national or even international market. This community service activity method is a training method consisting of coordination and discussion with the organizing agency, preparing materials, conducting outreach activities, evaluating activities, and compiling reports. This digital marketing socialization activity was given in five sessions. The division of training time makes it easier for participants to understand several digital marketing techniques, starting from the simplest, namely using Instant Messaging Marketing, social media, to opening an online store. The material is presented in simple language and examples that are easy for participants to understand and follow. Participants are invited to be active from the beginning of the activity, so that they can practice directly how to use digital applications to market their products. By participating in this socialization, participants who are home industri entrepreneurs are expected to be able to expand their product marketing digitally.
\end{abstract}

Keywords: digital marketing, home industri, Bangka Tengah

Copyright (c) 2021 Hilyah Magdalena, Hadi Santoso

$\triangle$ Corresponding author

Address : Jl. Jend. Sudirman Pangkalpinang

Email : hilyah@atmaluhur.ac.id

DOI : https://doi.org/10.31004/abdidas.v2i5.429

ISSN 2721-9224 (Media Cetak)

ISSN 2721- 9216 (Media Online) 
1055 Sosialisasi Pemasaran Digital Bagi Pelaku Industri Rumahan di Kabupaten Bangka Tengah - Hilyah Magdalena, Hadi Santoso

DOI: https://doi.org/10.31004/abdidas.v2i5.429

\section{PENDAHULUAN}

Industri rumahan merupakan salah satu usaha mikro yang banyak menyerap tenaga kerja perempuan, namun dalam pelaksanaannya belum banyak mendapat dukungan dari para pihak terkait; Pedoman Umum Pembangunan Industri Rumahan untuk Meningkatkan Kesejahteraan Keluarga Melalui Pemberdayaan Perempuan bertujuan untuk melaksanakan pembangunan industri rumahan yang terkoordinasi, efektif, dan efisien agar industri rumahan bertransformasi menjadi usaha kecil dan dapat menjadi sumber penghasilan dan peningkatan pendapatan, ketahanan keluarga serta kehidupan berkelanjutan (Peraturan Menteri PPPA Republik Indonesia No. 2 Tahun 2016, 2016).

Kondisi pandemi yang telah berlangsung selama 1,5 tahun ini berimbas cukup besar terhadap tingkat penghasilan pelaku industri rumahan yang ada di Kabupaten Bangka Tengah. Agar tingkat penjualan tidak semakin menurun, maka perlu strategi penjualan berbasis digital, agar pangsa pasar produk industri rumahan lebih luas. Industri rumahan di wilayah Kabupaten Bangka Tengah secara garis besar bergerak dibeberapa bidang berikut, batik tulis pakis, makanan khas, minuman, kerajinan (Diskominfosta Bateng, 2019).

Dinas Pemberdayaan Perempuan Keluarga Berencana Pengendalian Penduduk Perlindungan Anak (DPPKBPPPA) sebagai dinas yang menaungi pelaku industri rumahan, berinisitif untuk memberikan sosialisasi dan pelatihan pemasaran digital untuk pelaku industri rumahan agar meraka dapat bertahan selama masa pandemi ini. Memanfaatkan pemasaran digital adalah kebutuhan baru yang dapat mendorong laju pertumbuhan dan kelangsungan usaha industri rumahan. Keutamaan menggunakan pemasaran digital dalam memasarkan produk industri rumahan juga dilakukan di banyak daerah lain di Indonesia.

Di Randunagung Singosari Malang, ibu-ibu PKK merasakan manfaat pemasaran digital yang menjadi sebab naiknya omzet penjualan hasil industri rumahan berupa kerajinan tangan tangan dari bungkus minuman soda (Pradiani et al., 2017).

Berikutnya adalah pelaku usaha kecil di Gresik yang memanfaatkan media sosial sebagai sarana promosi untuk meningkatkan penjualan (Alfina, Marisya Mahdia Khoirina, 2020).

Selanjutnya, ada Garasi Kayu, pelaku usaha kecil di Kabupaten Purwakarta Jawa Barat, yang menerapkan pemasaran digital dengan aplikasi Googgle Bisnisku. Aplikasi ini membantu pelaku usaha kecil memperkenalkan usahanya dan agar mudah ditemukan oleh calon pembelinya (Dani Anggoro et al., 2020).

Peternak puyuh di Desa Gulaga, Kabupaten Bogor, berlatih menggunakan pemasaran digital sebagai sarana meningkatkan peluang pasar dari hasil produksi ternak puyuh (Rusmanah et al., 2019).

Pelaku industri kerajinan tas Aceh, kopi Aceh, dan masakan Aceh, memanfaatkan ecommerce untuk meningkatkan strategi pesamasaran. Pelaku industri kecul ini dilatih untuk mampu membangun e-commerce yang dibangun dengan aplikasi wordpress (Muhammad Bayu Wibawa, 2019). 
1056 Sosialisasi Pemasaran Digital Bagi Pelaku Industri Rumahan di Kabupaten Bangka Tengah - Hilyah Magdalena, Hadi Santoso

DOI: https://doi.org/10.31004/abdidas.v2i5.429

Pelaku usaha kecil yang bergerak di bidang kedai makanan di DKI Jakarta berkembang pesat, salah satunya di wilayah Kecamatan Kemayoran yaitu Jabet Sop. Pelaku industri dilatih untuk mampu memanfaatkan teknologi informasi dalam meningkatkan penjualan, seperti pemasaran lewat sosial media, menjadi merchant pada GrabFood dan GoFood dan berlatih membuat laporan keuangan yang akurat (Wahyuni et al., 2019).

Kelompok PKK Desa Sutojayan yang aktif memproduksi kerajinan tas dari tali kur, membuat bros, dan berbagai jenis keripik, telah berlatih memasarkan hasil produksinya tersebut menggunakan sosial media seperti FaceBook dan Instagram. Pelaku usaha kecil yang tergabung dalam Kelompok PKK Desa Sutojayan ini mampu memanfaatkan strategi pemasaran digital untuk memperkenalkan hasil produksi usahanya ke pasar yang lebih luas (Zulkha Ermayda et al., 2019).

Pelaku usaha kecil di Kecamatan Medan Denai Kota Medan, mendapat pelatihan dan pembinaan untuk memanfaatkan internet marketing sebagai media promosi agar mampu bersaing dalam memperluas pasar. Pelaku usaha kecil ini mampu memiliki website toko online dan memahami cara bertransaksi secara digital (Gultom et al., 2019).

Pelatihan untuk pelaku usaha kecil di Depok yang bergerak dibidang jasa kecantikan, rias pengantin, dan jual produk fashion, memanfaatkan media sosial untuk meningkatkan daya jual dan mendapatkan pelanggan baru. Media sosial mempermudah pelaku usaha kecil untuk mendesain foto promosi untuk meningkatkan penjualan (Mutia et al., 2019).
UKM snack 88 di Kota Solok memanfaatkan pemasaran digital untuk meningkatkan pemasaran produk dan mempermudah memantau kebutuhan serta keinginan calon konsumen. Pemasaran digital juga membantu calon konsumen untuk mencari produk (Irfani et al., 2020).

Pelaku UKM di Dusun Bukit Perjuangan Labuhanbatu, mendapat sosialisasi memanfaatkan sosial media seperti FaceBook, Instagram, Website, serta membuat akun berjualan di Marketplace (Bhakti Helvi Rambe, Fauziah Hanum, 2020).

Masyarakat di Keluran Tembalang yang menjadi pelaku usaha kecil sebagian besar memproduksi makanan buatan sendiri (homemade). Kendala pemasaran yang terbatas untuk produk makanan ini diatasi dengan memberikan pelatihan teknik memanfaatkan sosial media seperti facebook dan instagram untuk meningkatkan penjualan (Werdani et al., 2020).

Pendampingan untuk Jamaah Masjid Al Awwal Depok Jaya untuk mampu mempraktekkan pemasaran digital sebagai pendukung pemasaran. Pemasaran digital memanfaatkan berbagai sosial media seperti Facebook, Instagram, Gojek, Grab, dan aplikasi serupa lainnya (Iskandar Zulkarnain, Tabah Heri Setiawan, Budi Syamtoro, Muhamad Nurhamdi, 2020).

UMKM Makaroni Bajak Laut di Kabupaten Temanggung, berlatih menggunakan pemasaran digital untuk melakukan promosi. Pemasaran digital memanfaatkan sosial media dan Marketplace agar penjualan dapat meningkat dengan mempermudah proses pemesanan produk 
1057 Sosialisasi Pemasaran Digital Bagi Pelaku Industri Rumahan di Kabupaten Bangka Tengah - Hilyah Magdalena, Hadi Santoso

DOI: https://doi.org/10.31004/abdidas.v2i5.429

tanpa harus datang ke lokasi usaha (Sasongko et al., 2020).

Pelaku usaha di Ciputat, Tangerang Selatan, mengalami kesulitan memasarkan produknya selama masa pandemi Covid - 19. Kesulitan memasarkan produk diatasi dengan menguatkan branding produk dan memanfaatkan pemasaran digital (Diana \& Laila, 2020).

Pelaku usaha kecil di Desa Maor Kecamatan Kembangbahu mendapat pelatihan dan pendampingan pemasaran digital untuk membuka wawasan dan semangat untuk mengubah teknik pemasaran dari konvensional menjadi berbasis digital (Nanto Purnomo, 2020).

Pelaku usaha kecil di Desa Tales, Kabupaten Kediri, berlatih memasarkan produk dengan memanfaatkan sosial media sebagai media pemasaran digital. Pelaku usaha kecil yang telah memiliki sosial media dilatih untuk bisa memisahkan akun pribadi dengan akun toko online (Juli Sulaksono, 2020).

Pengusaha Muslim di Korwil Dau Malang adalah mitra dengan anggota cukup besar, namun belum memanfaatkan teknologi informasi secara maksimal. Pelatihan pemasaran digital untuk pengusaha muslim membuat mereka mampu merancang website dan mendaftarkan usaha (Febriani et al., 2021).

Pemuda yang baru memulai bisni di Karang Taruma Pertama Alam Permai Gadangan Sidoarjo mendapat pelatihan memanfaatkan sosial media dan Marketplace untuk mendukung mengembangkan bisnis agar bisnis yang bari dirintis dapat lebih cepat berkembang dan dikenal masyarakat luas (Rudi Santoso, Achmad Yanu Alif Fianto, 2020).

Pelaku usaha kecil di Desa Sayang Kecamatan Jatinangor mengembangkan teknik pemasarannya berbasis teknologi untuk dapat bersaing dengan usaha - usaha sejenis yang sudah online. Usaha mengembangkan pemasaran berbasis online ini memanfaatkan aplikasi seperti Grab Food dan Go Food (Susanti, 2020).

Industri rumahan produksi emping di Kampung Pagutan Desa Sukakerta Cianjur mengalami kendala pemasaran selama pandemi. Kendala pemasaran ini diatasi dengan mengubah cara memasarkan produk dari konvensional menjadi memasarkan secara digital dengan pelatihan bisnis model canvas, pemasaran digital dan media peralatan penunjang usaha lainnya (As'ary et al., 2021).

Pengrajin cetakan kue di Desa Candi Kabupaten Sidoarjo adalah pelaku usaha kecil yang membutuhkan pemasaran digital untuk mendorong pemasaran agar dapat menjangkau pembeli lebih luas(Zulifah Chikmawati, Atik Widiyanti, 2020).

Pelaku usaha di Kabupaten Karawang yang mempunyai produk unggulan, membutuhkan sosial media sebagai media promosi dan menunjang pemasaran dengan jangkauan pembeli lebih luas. Beberapa pelaku usaha telah memanfaatkan sosial media namun belum optimal memanfaatkan fitur fitur tertentu dari sosial media. Untuk meningkatkan kemampuan pelaku usaha mengoptimalkan pemasaran digital dalam memajukan usahanya, maka mereka mendapatkan pelatihan dan pendampingan yang memadai agar 
1058 Sosialisasi Pemasaran Digital Bagi Pelaku Industri Rumahan di Kabupaten Bangka Tengah - Hilyah Magdalena, Hadi Santoso

DOI: https://doi.org/10.31004/abdidas.v2i5.429

omzet penjualan meningkat (Hendriadi et al., 2019).

Berdasarkan kondisi kebutuhan pelaku industri rumahan di Bangka Tengah, dan banyaknya pelaku industri rumahan, maupun industri kecil menengah di berbagai daerah di Indonesia yang telah mendapatkan pelatihan memanfaatkan pemasaran digital untuk meningkatkan penjualan, maka kegiatan pengabdian masyarakat kali ini fokus pada upaya memberikan sosialisasi pemanfaatan pemasaran digital bagi pelaku industri rumahan yang berada di Kabupaten Bangka Tengah. Sosialisasi ini bertujuan untuk mengenalkan beberapa model pemasaran digital kepada para pelaku industri rumahan. Dengan memberikan beberapa pilihan pemasaran digital, diharapkan para pelaku industri rumahan dapat memilih model pemasaran digital seperti apa yang sesuai untuk diterapkan di industri rumahan yang dikelolanya.

\section{METODE}

Metode yang digunakan dalam kegiatan pengabdian masyarakat ini adalah metode pelatihan. Mengingat situasi masih dalam pandemi, maka pihak Dinas Pemberdayaan Perempuan Keluarga Berencana Pengendalian Penduduk Perlindungan Anak (DPPKBPPPA) sebagai dinas yang menaungi pelaku industri rumahan di Kabupaten Bangka Tengah menetapkan sosialisasi berlangsung dengan memperhatikan protokol kesehatan, dan dilakukan secara singkat, padat, dan tepat sasaran. Berikut ini adalah tahap-tahap kegiatan pengabdian masyarakat :
1. Melakukan koordinasi dan diskusi dengan pihak Dinas Pemberdayaan Perempuan Keluarga Berencana Pengendalian Penduduk Perlindungan Anak (DPPKBPPPA) sebagai penggagas kegiatan untuk mengetahui bentuk materi sosialisasi pemasaran digital yang dibutuhkan pelaku industri rumahan di Kabupaten Bangka Tengah.

2. Mempersiapkan materi sosialisasi pemasaran digital sesuai dengan hasil diskusi dengan pihak Dinas Pemberdayaan Perempuan Keluarga Berencana Pengendalian Penduduk Perlindungan Anak

$(D P P K B P P P A)$ Kabupaten Bangka Tengah.

3. Melaksanakan sosialisasi sesuai tanggal yang telah ditentukan. Sosialisasi dilaksanakan pada hari Kamis, tanggal 17 Juni 2021dari jam 08.00 -15.00, di Ruang Pertemuan Hotel Osela Jln. Raya Koba Kel. Dul, Kecamatan Pangkalan Baru, Kabupaten Bangka Tengah, Provinsi Kep. Bangka Belitung.

4. Evaluasi kegiatan, untuk menilai kesesuaikan pelaksanaan kegiatan dengan rencana yang telah dibuat sebelumnya. Evaluasi ini juga menjadi masukan bagi pihak dinas selaku penggagas kegiatan.

5. Penyusunan laporan kegiatan pengabdian masyarakat, sebagai bentuk pertanggungjawaban resmi kegiatan pengabdian masyarakat. Laporan diserahkan di PPM Institut Sains dan Bisnis Atma Luhur.

\section{HASIL DAN PEMBAHASAN}

Kegiatan sosialisasi pemasaran digital bagi pelaku industri rumahan di Kabupaten Bangka 
1059 Sosialisasi Pemasaran Digital Bagi Pelaku Industri Rumahan di Kabupaten Bangka Tengah - Hilyah Magdalena, Hadi Santoso

DOI: https://doi.org/10.31004/abdidas.v2i5.429

Tengah diikuti oleh 50 orang. Peserta berasal dari beberapa kecamatan di Kabupaten Bangka Tengah yang teknis penunjukan peserta dikoordinir oleh Dinas Pemberdayaan Perempuan Keluarga Berencana Pengendalian Penduduk Perlindungan Anak (DPPKBPPPA) Kabupaten Bangka Tengah. Pembukaan acara sosialisasi dilakukan oleh Kepala Dinas DPPKBPPPA Kabupaten Bangka Tengah, dan dihadiri oleh perwakilan staf bidang Industri Rumahan Dinas DP3ACSKB Provinsi Kep.Bangka Belitung.

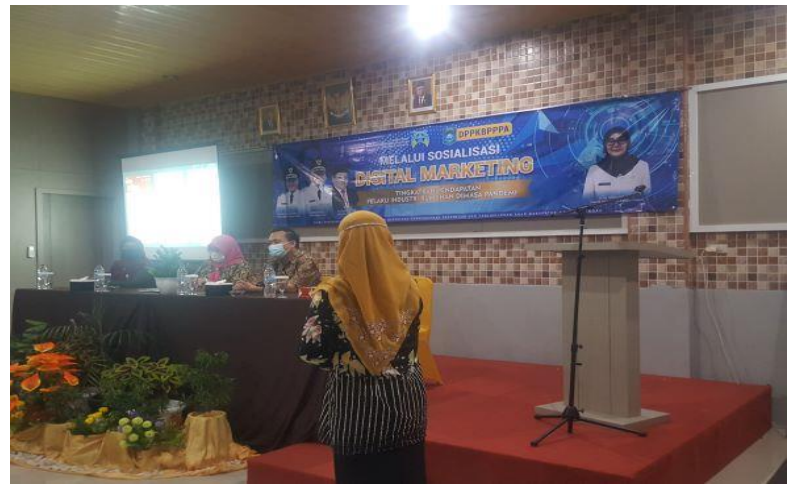

Gambar 1. Pembukaan Sosialisasi

Kegiatan sosialisasi berlangsung satu hari, dengan cakupan materi berupa pengenalan pemasaran digital secara umum. Sesi pertama ini bertujuan memperkenalkan secara singkat apa yang dimaksud dengan pemasaran digital, bentukbentuk pemasaran digital, dan kelebihan serta kekurangan tiap-tiap jenis pemasaran digital.

Pada sesi pertama, tim dosen dari ISB Atma Luhur juga aktif mengamati sejauh apa para peserta mampu memahami materi dan juga mencatat seberapa banyak peserta yang telah memanfaatkan layanan pemasaran digital. Peserta secara umum telah mengenal media sosial dan juga telah mempunyai alamat email. Kondisi telah memiliki akun media sosial dan alamat email memudahkan tim instruktur untuk memperkenalkan teknik pemasaran digital lainnya.

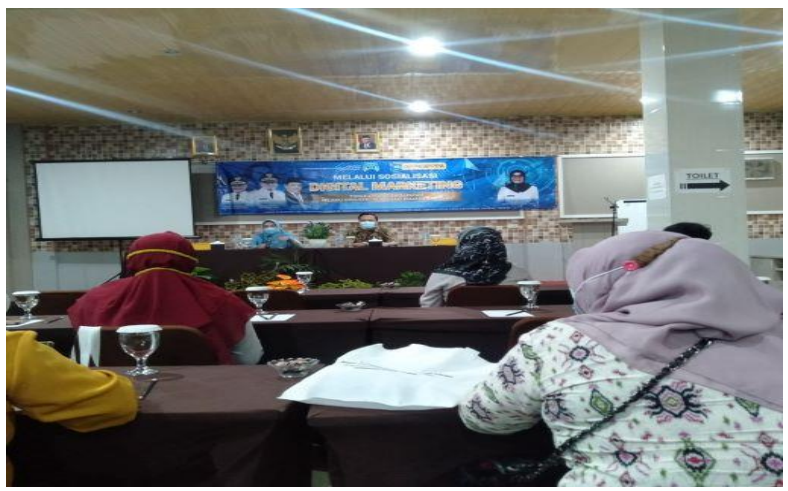

Gambar 2. Sosialisasi Pemasaran digital Sesi 1

Pada sesi kedua, sosialisasi pemasaran digital mulai dari teknik pemasaran yang paling mudah diterima secara umum oleh pelaku industri rumahan yaitu Instant Messaging Marketing, yaitu teknik memasarkan produk dengan memanfaatkan jaringan pertemanan yang ada di aplikasi instant messaging, seperti seperti Whatsapp, LINE, atau Facebook Messenger. Teknik ini mudah digunakan dan jika mempunyai jaringan pertemanan luas, hal ini cukup menguntungkan.

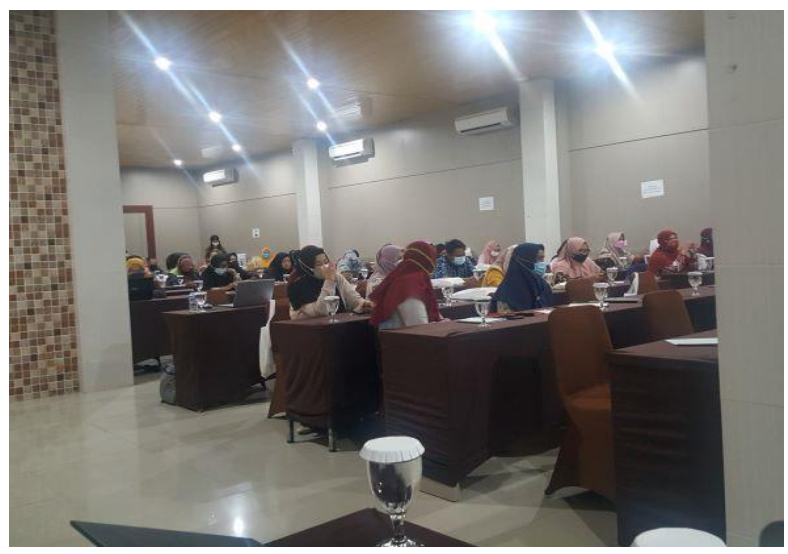

Gambar 3. Sosialisasi Pemasaran digital Sesi 2 
1060 Sosialisasi Pemasaran Digital Bagi Pelaku Industri Rumahan di Kabupaten Bangka Tengah - Hilyah Magdalena, Hadi Santoso

DOI: https://doi.org/10.31004/abdidas.v2i5.429

Pada sesi ketiga, sosialisasi dilanjutkan dengan mengenal teknik sosial media marketing. Saat ini memanfaatkan sosial media sebagai sarana memasarkan produk adalah strategi tepat dan relatif mudah, terlebih saat pandemi yang membatasi kegiatan sosial. Peserta sosialisasi dikenalkan dengan beragam platform sosial media seperti Instagram, Twitter, Facebook. Peserta diberikan beberapa saran dalam memilih sosial media yang sesuai dengan target pasar. Misalnya, anjuran memilih Instagram untuk pelaku usaha yang menekankan pada visual seperti produk pakaian dan makanan. Sosial media juga ampuh menjadi sarana promosi dan tidak memerlukan biaya pemasaran.

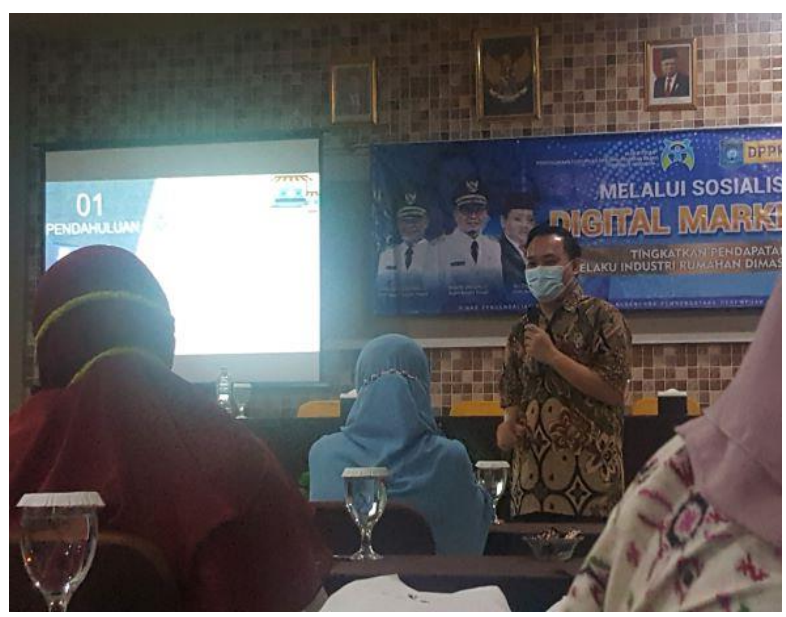

Gambar 4. Sosialisasi Pemasaran digital Sesi 3

Pada sesi keempat, sosialiasi focus pada teknik pemasaran digital berikutnya, yaitu email marketing. Email marketing ini terutama ditujukan kepada pelaku industri rumahan yang telah mempunyai pelanggan tetap, dan menggunakan email marketing untuk menyampaikan penawaran langsung seperti promo, update produk baru, maupun untuk meningkatkan interaksi dengan pelanggan.

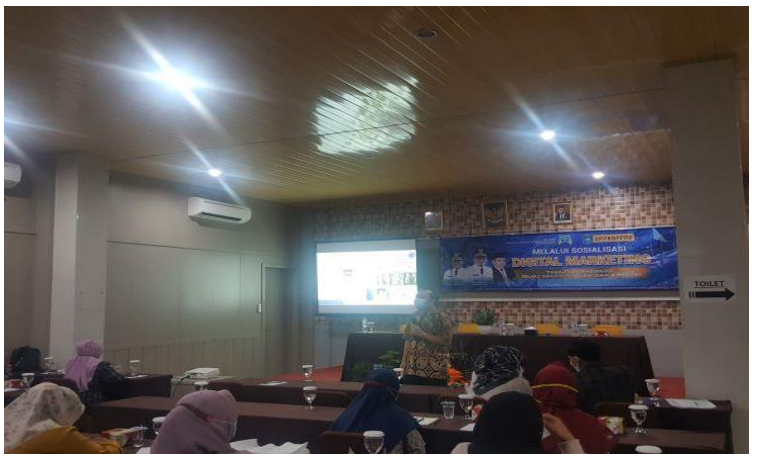

Gambar 5. Sosialisasi Pemasaran digital Sesi 4

Selanjutnya di sesi kelima, materi sosialisasi masuk tahap mendemokan tahap-tahap memanfaatkan pemasaran digital yang berbasis $e$ commerce. Pemasaran digital berbasis e-commerce ini dipilih karena kuatnya promosi yang di dukung e-commerce dapat meningkatkan penjualan ke toko online. Selain itu banyaknya layanan dan bonus yang diberikan e-commerce juga menarik banyak pembeli. Pada tahap ini peserta diarahkan untuk memahami bagaimana memanfaatkan toko online di e-commerce. Setelah peserta tertarik, kemudian instruktur mendemokan cara membuat toko online dan cara memperbarui informasi produk serta memoles informasi tentang produk agar menarik. Peserta diminta untuk mencoba lansung di gadget yang mereka punya dan mereka dapat melanjutkan penyempurnaan toko online berkelanjutan. 


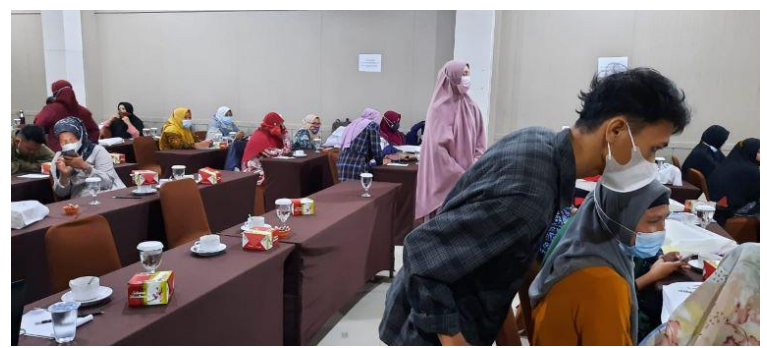

Gambar 6. Sosialisasi Pemasaran digital Sesi 5

Pada akhir sesi dibuka tanya jawab untuk memastikan penerimaan materi sosialisasi ini. Peserta diberi kesempatan untuk bertanya jika ada kendala atau materi yang kurang dipahami.

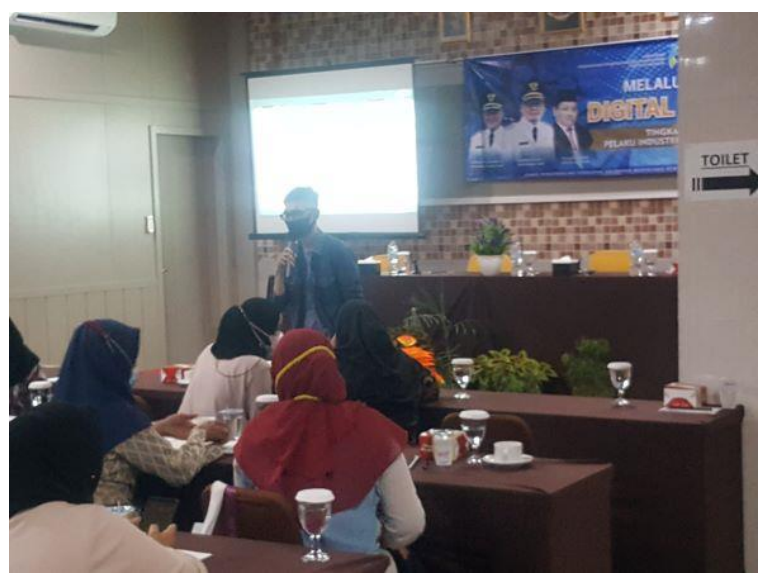

Gambar 7. Sesi Tanya Jawab

Diakhir acara, kegiatan sosialisasi ini mendapat simpulan dan ucapan terima kasih dari Kepala Dinas terkait. Simpulan dari Ibu Kepala Dinas juga menjadi motivasi bagi pelaku industri rumahan yang sebagian besar pelakunya adalah perempuan atau khususnya adalah ibu rumah tangga yang memanfaatkan waktunya untuk ikut menopang ekonomi keluarga. Dukungan dari pihak dinas terkait untuk kemajuan industri rumahan di Kabupaten Bangka Tengah, dan juga undangan kerja sama untuk dosen Institut Sains dan Bisnis Atma Luhur telah mampu meningkatkan pemahaman pemasaran digital. Pelaku usaha industri rumahan yang sebagian besar telah mempunyai akun media sosial, dapat meningkatkan fungsi media sosialnya menjadi media memasarkan produk. Bagi pelaku industri rumahan yang memilih menggunakan toko online, kami selaku instruktur menganjurkan agar memperhatikan perjanjian yang disepakati dengan pihak e-commerce.

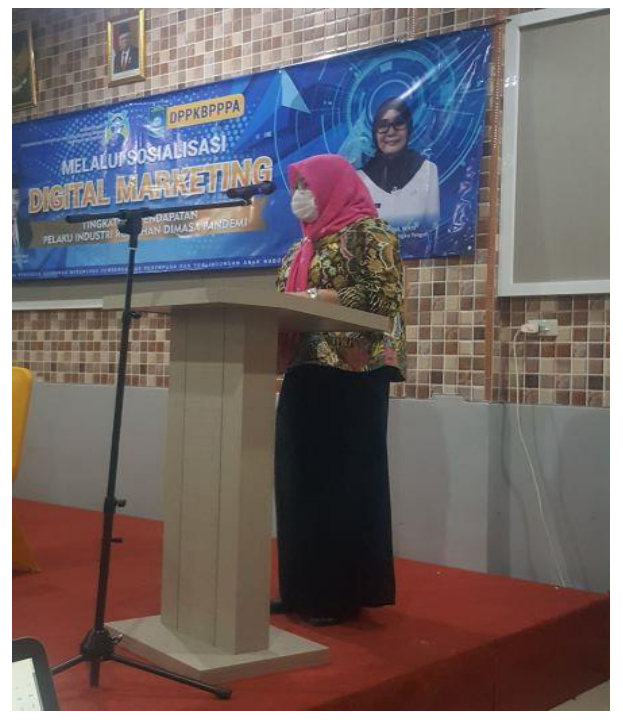

Gambar 8. Pengarahan dan Simpulan Kegiatan oleh Ka. Dinas DPPKBPPPA Kab. Bangka Tengah

Kegiatan sosialisasi pemasaran digital yang dilakukan untuk mendukung pelaku industri rumahan memasarkan produknya secara digital, berlangsung lancar sesuai dengan rencana.

\section{SIMPULAN}

Kegiatan sosialisasi pemasaran digital produk industri rumahan di Kabupaten Bangka Tengah memberikan tambahan pengetahuan tentang pilihan memasarkan produk. Produk hasil 
1062 Sosialisasi Pemasaran Digital Bagi Pelaku Industri Rumahan di Kabupaten Bangka Tengah - Hilyah Magdalena, Hadi Santoso

DOI: https://doi.org/10.31004/abdidas.v2i5.429

industri rumahan yang selama ini dipasarkan secara local diharapkan dapat dipasarkan lebih luas dengan dukungan pemasaran digital. Latar belakang pendidikan dan kondisi ekonomi yang beragam, membuat tim instruktur dari ISB Atma Luhur memberikan materi berupa beberapa pilihan teknik pemasaran digital, mulai dari yang paling mudah yaitu menggunakan pesan singkat di aplikasi sosial media sampai membuka toko online di jaringan e-commerce. Pengetahuan tentang pemasaran digital ini semoga dapat menambah luas kemampuan perempuan-perempuan penggerak usaha industri rumahan, agar mampu meningkatkan daya saing dan kualitas produknya.

\section{UCAPAN TERIMA KASIH}

Terima kasih kepada Dinas Pemberdayaan Perempuan Keluarga Berencana Pengendalian Penduduk Perlindungan Anak (DPPKBPPPA) sebagai dinas yang menaungi pelaku industri rumahan di Kabupaten Bangka Tengah yang telah memberikan kesempatan kepada tim dosen dan mahasiswa dari Institut Sains dan Bisnis Atma Luhur untuk berbagi ilmu dan pengetahuan tentang pemasaran digital kepada para pelaku industri rumahan.

\section{DAFTAR PUSTAKA}

Alfina, Marisya Mahdia Khoirina, T. A. N. (2020). Pelatihan Pemasaran digital bagi Entrepreneur Di Kota Gresik. Jurnal Abdidas, 1(6), 761769.

As'ary, M., Mugini, P., Fakhrurozi, Muhammad Fikri, Sugiarti, G. F. U., \& Hapsari, D. R. H. (2021). Optimalisasi Potensi Home Industri melalui Digitalisasi Marketing (Kasus: Produksi Emping Rumahan Kampung
Pagutan, Desa Sukakerta, Cianjur). Jurnal Pusat Inovasi Masyarakat, 3(1), 91-101. https://journal.ipb.ac.id/index.php/pim/article/ view/35352

Bhakti Helvi Rambe, Fauziah Hanum, Y. P. (2020). PELATIHAN MANAJEMEN PEMASARAN BERBASIS ONLINE DI DUSUN BUKIT PERJUANGAN KABUPATEN LABUHANBATU. Minda Baharu, 4(2), 131-138.

Dani Anggoro, Humisar Hasugian, \& Nofiyani. (2020). Implementasi Pemasaran digital Pada UKM Guna Meningkatkan Pemasaran dan Penjualan Produk Di Masa Pandemi Covid19. JURPIKAT (Jurnal Pengabdian Kepada Masyarakat), 1(3), 384-391. https://doi.org/10.37339/jurpikat.v1i3.345

Diana, \& Laila, N. (2020). Strategi Pengembangan Usaha Home Industri Makanan Sebagai Peluang Pendapatan di Masa Pandemi Covid19. Prosiding Seminar Nasional Pengabdian Masyarakat LPPM UMJ, 1(1), 1-8. http://jurnal.umj.ac.id/index.php/semnaskat

Diskominfosta Bateng. (2019). Usaha Kecil Menengah / Industri Kecil Menengah. https://bangkatengahkab.go.id/halaman/detail/ usaha-kecil-menengah--industri-kecilmenengah

Febriani, R., Lestari, N. P., \& Yuliati, U. (2021). Pendampingan Pengelolaan Pemasaran digital Pengusaha Muslim Korwil Dau Malang. Studi Kasus Inovasi Ekonomi, 05(01), 61-66.

Gultom, D. K., Pulungan, D. R., \& Farisi, S. (2019). Pembinaan dan Pendampingan Internet Marketing Guna Peningkatan Daya Saing pada Usaha Mikro Handycraft di Kota Medan. JPM (Jurnal Pemberdayaan Masyarakat), 4(1), 339-347. https://doi.org/10.21067/jpm.v4i1.2700

Hendriadi, A. A., Sari, B. nurina, \& Padilah, T. N. (2019). Pelatihan Pemasaran digital Usaha Mikro, Kecil dan Menengah (UMKM) di Kabupaten Karawang. J-Dinamika: Jurnal Pengabdian Masyarakat, 4(2), 120-125. https://doi.org/10.25047/j-dinamika.v4i2.1133

Irfani, H., Yeni, F., \& Wahyuni, R. (2020). Pemanfaatan Pemasaran digital Sebagai Strategi Pemasaran Pada Ukm Dalam 
1063 Sosialisasi Pemasaran Digital Bagi Pelaku Industri Rumahan di Kabupaten Bangka Tengah - Hilyah Magdalena, Hadi Santoso

DOI: https://doi.org/10.31004/abdidas.v2i5.429

Menghadapi Era Industri 4.0. JCES (Journal of Character Education Society), 3(3), 651659.

Iskandar Zulkarnain, Tabah Heri Setiawan, Budi Syamtoro, Muhamad Nurhamdi, I. S. O. (2020). Penerapan Pemasaran digital Sebagai Strategi Komunikasi Pemasaran Usaha Kecil dan Menengah Warga Depok Jaya. Jurnal IMPACT: Implementation and Action, 2(2), 39. https://doi.org/10.31961/impact.v2i2.844

Juli Sulaksono, N. Z. (2020). Peranan Pemasaran digital Bagi Usaha Mikro, Kecil, Dan Menengah (Umkm) Desa Tales Kabupaten Kediri. Generation Journal, 4(1), 41-47. https://doi.org/10.29407/gj.v4i1.13906

Peraturan Menteri PPPA Republik Indonesia No. 2 Tahun 2016, 4 (2016).

Muhammad Bayu Wibawa, F. (2019). PELATIHAN E-COMMERCE BAGI UMKM ACEH E-COMMERCE TRAINING FOR ACEH SMEs. Pengabdian Masyarakat, l(2), 100-104.

Mutia, I., Yulianingsih, Y., \& Cholifah, W. N. (2019). Tata Kelola Media Sosial sebagai Pendukung Peningkatan Daya Jual Produk Industri Rumahan. Jurnal PkM Pengabdian Kepada Masyarakat, 2(01), 56. https://doi.org/10.30998/jurnalpkm.v2i01.275 9

Nanto Purnomo. (2020). Peningkatan Sumber Daya Manusia Melalui Pelatihan. Pemanfaatan Teknologi Dalam Proses Pembelajaran Menuju Pembelajaran Abad 21, 2, 999-1015.

Pradiani, T., Penjualan, V., \& Malang, S. (2017). PENGARUH SISTEM PEMASARAN PEMASARAN DIGITAL TERHADAP PENINGKATAN VOLUME PENJUALAN HASIL INDUSTRI RUMAHAN. JIBEKA, 11(2), 46-53.

Rudi Santoso, Achmad Yanu Alif Fianto, N. A. (2020). PEMANFAATAN PEMASARAN DIGITAL UNTUK PENGEMBANGAN BISNIS PADA KARANG TARUNA PERMATA ALAM PERMAI GEDANGAN SIDOARJO PEMASARAN DIGITAL FOR BUSINESS DEVELOPMENT IN KARANG TARUNA PERMATA ALAM PERMAI
GEDANGAN SIDOARJO Universitas Dinamika , Surabaya , Indonesia. Jurnal Layanan Masyarakat, 4(2), 326-338.

Rusmanah, E., Irawan, A. W., \& Andria, F. (2019). Implementasi Pemasaran digital Guna Peningkatan Peluang Pasar Produksi Hasil Ternak Puyuh Masyarakat Desa Galuga. Jurnal ABM Mengabdi, 6(1), 14-25.

Sasongko, D., Putri, I. R., Alfiani, V. N., Qiranti, S. D., Sari, R. S., \& Allafa, P. E. (2020). Pemasaran digital Sebagai Strategi Pemasaran UMKM Makaroni Bajak Laut Kabupaten Temanggung. Jurnal Ilmiah Pangabdhi, 6(2), 92-96.

https://doi.org/10.21107/pangabdhi.v6i2.7809

Susanti, E. (2020). Pelatihan Pemasaran digital Dalam Upaya Pengembangan Usaha Berbasis Teknologi Pada Umkm Di Desa Sayang Kecamatan Jatinangor. Sawala: Jurnal Pengabdian Masyarakat Pembangunan Sosial, Desa Dan Masyarakat, 1(2), 36. https://doi.org/10.24198/sawala.v1i2.26588

Wahyuni, S., Mudiar, W., \& Masrifa, A. Y. A. (2019). Pemasaran digital Training and Assistance for SMEs as an Effort to Improve the Jabet Sop Sales Service. MITRA: Jurnal Pemberdayaan Masyarakat, 3(2), 195-203. https://doi.org/10.25170/mitra.v3i2.890

Werdani, R. E., Kurniawati, N. I., Sukoco, J. B., Windriya, A., \& Iskandar, D. (2020). Pelatihan Pemasaran Produk Homemade Melalui Sosial Media. JPPM (Jurnal Pengabdian Dan Pemberdayaan Masyarakat), $4(1), \quad 1$. https://doi.org/10.30595/jppm.v4i1.4655

Zulifah Chikmawati, Atik Widiyanti, C. L. W. (2020). PELATIHAN PEMASARAN DIGITAL BAGI PENGRAJIN CETAKAN KUE DI DESA CANDI KABUPATEN SIDOARJO. Journal of Science and Social Development, 3(2), 1-9.

Zulkha Ermayda, R., Ikrima Nanda, H., \& Dwi Narullia. (2019). Pemasaran digital Sebagai Strategi Pemasaran Produk Pkk. Jurnal Pengabdian UntukMu NegeRI, 3(2), 80-84. https://doi.org/10.37859/jpumri.v3i2.1506 